\title{
ANALYSIS OF PARAMETERS SERIES OF WIRE CROSS- SECTIONS FOR OVERHEAD POWER LINE DESIGN
}

\author{
Veronika Cherkashyna \\ Department "Electric power transmission" \\ National technical university «Kharkiv polytechnic institute» \\ 21 Frunze str., Kharkiv, Ukraine, 61002 \\ cherk34@rambler.ru
}

\begin{abstract}
In the analysis of the parameters series of wire cross-sections for the overhead power line design taking into account their development prospects, the author solved the following tasks. The study of the existing parameter, which characterizes and determines the optimization option of the technical and economic model for the design of overhead lines, which allowed showing the unreasonableness of using the economic current density as the basic optimization parameter of the technical and economic model of overhead lines is performed. The wire cross-section as the basic optimization parameter of the technical and economic model of overhead lines is proposed. The scale growth factor of the parameters series of wire cross-sections is obtained by the criteria-based method, which allowed developing an optimum scale of wire cross-sections. Estimation of the statistical characteristics of the distribution of the relative value of wire cross-sections is carried out. The introduced hypothesis of a log-normal distribution law of the current density is tested using the Pearson's chi-squared test for finding the relationship of relative variation of the initial information on the scale growth factor of wire cross-sections. The effect of the optimum scale of wire cross-sections on the regulations of reconstruction, which is due to the load rate and growth variations in the power grid is determined.

Keywords: overhead line, wire cross-section, technical and economic model, criteria-based method, Pearson's chi-squared test.

\section{Introduction}

Operation conditions of the electric power industry dictate the need for the power grid (PG) facilities, including overhead power lines (OL) to be optimally designed, which means economically feasible taking into account the technical parameters and development prospects of facilities. Therefore, variations in the OL parameters over time, the variation dynamics of which depends on the load rate and growth should be considered.

For the OL design, it is necessary to select economically feasible parameter values, which are determined in the implementation of technical and economic models and reflect the specifics and development prospects of the facility. In addition, the issues of economic stability and sensitivity of solving such problems, allowing some deviations from the resulting optimum option, as well as taking into account variations in economically feasible parameters over time, which predetermines the OL development strategy and tactics are relevant.
\end{abstract}

(C) Veronika Cherkashyna

\section{Literature review and problem statement}

The problems of optimization of PG facilities are relevant for both the EU countries and Ukraine. The development strategy of the electric power industry is based on the principle of optimization and unification, including of a number of components of the power grid equipment [1]. In [2], the issues of unification of PG with distributed generation sources are considered, but the OL optimization problems are not sufficiently disclosed. In [3], the problems of optimization of the parameters series of wire cross sections of $110-750 \mathrm{kV}$ OL are examined, but estimation of the relationship of the initial information variation on the scale growth factor of wire cross sections is not performed.

Selection of optimization parameters requires an integrated approach, which is especially needed in the OL analysis. Since the parameters of the lines depend not only on the PG operation modes, but also load variations in the PG over time. A comprehensive analysis for the OL design 
taking into account their development prospects involves the implementation of technical and economic models, which gives a complete behavior pattern of the optimization parameters.

This problem can be solved using the methods of dynamic and linear programming, which allow finding the optimum development plan of OL. The difficulty of solution is caused by the fact that the dynamic programming is ineffective in implementing the model that contains more than three optimization parameters. Linear programming implements linear models, which certainly distorts the actual functional relationship within the optimization object, since linear models linearize all existing nonlinear dependencies $[4,5]$.

The advent of the criteria-based programming methods made possible the analysis of nonlinear technical and economic models of OL $[6,7]$. The experimental design technique and mathematical statistics allow checking the initial information variation on the optimization parameters [8-10].

\section{Research purpose and objectives}

The purpose of the research is to analyze the parameters series of wire cross-sections for the design of overhead power lines taking into account their development prospects.

To achieve the purpose, it is necessary to solve the following tasks:

- to examine the existing parameter, which characterizes and determines the optimization option of the technical and economic model for the overhead line design;

- to propose the optimization parameter of the technical and economic model of overhead lines, which takes into account the load rate and growth variations in the power grid;

- to justify the scale growth factor of wire cross-sections and develop the optimum parameters series for the overhead line design taking into account their development prospects;

- to estimate the statistical characteristics of the distribution of the relative value of wire cross-sections for finding the relationship of the initial information variation on the scale growth factor of wire cross-sections of overhead lines;

- to determine the effect of the optimum scale of wire cross-sections on the regulations of reconstruction, which is due to the load rate and growth variations in the power grid.

4. Research materials and methods, which substantiate the effect of the scale of wire crosssections on the technical and economic model optimization for the overhead line design

4. 1. Materials and methods of studying the parameter, which characterizes and determines the optimization option of the technical and economic model of overhead power lines

The economic current density of OL is mainly used today as the parameter, which characterizes and determined the optimization option of the technical and economic model for the OL design [11].

Using the economic current density [11], the analysis of the OL parameters on the example of $10 \mathrm{kV}$ OL in several PG in the eastern Ukraine is performed. In the analysis, the assumption is made that the current density occurrence on a site of lines is a random variable.

The results are presented in the form of statistical series and given in Table $\mathbf{1}$.

Table 1

The statistical series for the sample values of $10 \mathrm{kV}$ OL

\begin{tabular}{cccccc}
\hline $\mathbf{l}_{\mathbf{i}}$ & $\mathbf{m}_{\mathbf{i}}$ & $\mathbf{P}_{\mathbf{i}}^{*}$ & $\mathbf{l}_{\mathbf{i}}$ & $\mathbf{m}_{\mathbf{i}}$ & $\mathbf{P}_{\mathbf{i}}^{*}$ \\
\hline $0 \div 0,1$ & 5 & 0,038 & $0,5 \div 0,6$ & 10 & 0,08 \\
$0,1 \div 0,2$ & 24 & 0,18 & $0,6 \div 0,7$ & 8 & 0,06 \\
$0,2 \div 0,3$ & 18 & 0,14 & $0,7 \div 0,8$ & 11 & 0,083 \\
$0,3 \div 0,4$ & 23 & 0,17 & $0,8 \div 0,9$ & 6 & 0,045 \\
$0,4 \div 0,5$ & 20 & 0,155 & $0,9 \div 1,2$ & 6 & 0,045
\end{tabular}

Note: $l_{i}$ is the range of current density values; $m_{i}$ is the number of observations in the given range; $P_{i}^{*}$ is the corresponding frequency of occurrences 
To analyze the OL parameters, the author introduced the hypothesis:

$H_{0}$ - the distribution law of the studied statistics is lognormal.

The lognormal distribution is determined by two parameters: $\mathrm{j}_{0}$ and $\sigma_{\mathrm{z}} \lg \mathrm{j}_{0}$ represents the expected value of a random variable $\overline{\mathrm{m}}=\lg \mathrm{j}$, and $\sigma_{\mathrm{z}}$ - its standard deviation.

Knowing the distribution parameters, the probability of the frequency $P_{i}$ of the random variable I falling within the range between $\alpha$ and $\beta$ is determined according to the expression:

$$
\mathrm{P}_{\mathrm{i}}(\alpha<\mathrm{j}>\beta)=\Phi\left(\frac{\beta-\overline{\mathrm{m}}}{\sigma}\right)-\Phi\left(\frac{\alpha-\overline{\mathrm{m}}}{\sigma}\right),
$$

where $\overline{\mathrm{m}}=\lg \mathrm{j}_{0}=-0,4368 ; \sigma=\sigma_{\mathrm{z}}=-0,2880 ; \beta=\lg \mathrm{j}_{\mathrm{i}+1} ; \alpha=\lg \mathrm{j}_{\mathrm{i}} ; \mathrm{j}_{\mathrm{i}}$ is the boundary value of the current density on the ranges [12].

The calculation results (1) in the form of statistical series for the estimated values are presented in Table 2.

Table 2

The statistical series for the estimated values of $10 \mathrm{kV} \mathrm{OL}$

\begin{tabular}{cccc}
\hline $\mathbf{l}_{\mathbf{i}}$ & $\mathbf{P}_{\mathbf{i}}{ }^{*}$ & $\mathbf{l}_{\mathbf{i}}$ & $\mathbf{P}_{\mathbf{i}}{ }^{*}$ \\
\hline $0 \div 0,1$ & 0,067 & $0,5 \div 0,6$ & 0,08 \\
$0,1 \div 0,2$ & 0,156 & $0,6 \div 0,7$ & 0,076 \\
$0,2 \div 0,3$ & 0,205 & $0,7 \div 0,8$ & 0,045 \\
$0,3 \div 0,4$ & 0,165 & $0,8 \div 0,9$ & 0,031 \\
$0,4 \div 0,5$ & 0,134 & $0,9 \div 1,2$ & 0,053
\end{tabular}

Note: $1_{\mathrm{i}}$ is the range of current density values; $m_{i}$ is the number of estimated observations in the given range; $\mathrm{P}_{\mathrm{i}}^{*}$ is the corresponding frequency of occurrences

Using (1), it was found that the introduced hypothesis does not contradict the actual data presented in Table 1, since the estimate of the expected value of the current density is $=-4368$ and $=0,365 \mathrm{~A} / \mathrm{mm}^{2}$.

To analyze the criterion by the statistical series (Table 2), the following is set:

- the number of degrees of freedom $n=k-2=10-2=8$;

- the level of significance $\alpha=0,05$.

To test the hypothesis, the Pearson's chi-squared test $\left(\chi^{2}\right)$ is used.

$$
\chi^{2}=\mathrm{N} \sum_{\mathrm{i}=1}^{\mathrm{k}} \frac{\left(\mathrm{P}_{\mathrm{i}}^{*}-\mathrm{P}_{\mathrm{i}}\right)^{2}}{\mathrm{P}_{\mathrm{i}}},
$$

where $\chi^{2}$ is the Pearson's chi-squared test; $\mathrm{N}=125$ is a set of random numbers; $\mathrm{k}$ is the number of ranges; $\mathrm{P}_{\mathrm{i}}^{*}$ is the corresponding frequency of occurrences; $\mathrm{P}_{\mathrm{i}}$ is the probability of the random variable falling within the range [10].

Calculation by (2) gave the value of the Pearson's chi-squared test $\chi^{2}=10,41$.

The critical Pearson's chi-squared test statistics for $\mathrm{n}=8$ and $\alpha=0,05$ has the values $\chi^{2}=15,51$ [10].

Since $10.41<15.51$, the decision is made:

$\gamma_{0}$-the null hypothesis is not rejected.

Based on the lognormal current-density distribution law, the range of current density values is determined. This range appeared quite large $(0,1 \div 1,2) \mathrm{A} / \mathrm{mm}^{2}$, so the resulting value can not be considered as the range of economic stability, since almost any value of the current density in this range will be economically feasible, which is obviously incorrect.

This value of the range is the result of the non-simultaneous start of PG operation. For the optimum parameter to be taken as the economic current density, its value should be maintained in all the PG sites, which is virtually impossible due to the discrete nature of the scale of wire cross-sections, as well as the load current, varying from site to site. 
The research has confirmed the need to take into account the discrete nature of the scale of wire cross-sections to optimize the technical and economic models of OL when designing economically feasible values of OL parameters considering their development prospects.

\section{2. Research materials and methods that allow developing the optimum scale of wire} cross-sections for the overhead line design

The author proposed the wire cross-section as the basic optimization parameter and made the assumption that the load distribution over the area is uniform.

One of the criteria for selecting the optimum option of the OL design is minimum discount costs. Given this criterion, as well as the proposed optimization parameter, the technical and economic model of discount costs $\left(3_{\mathrm{i}}\right)$ of OL is enhanced, the main feature of which is the change of the analytical relationship of investments in OL with the wire cross-section (F):

$$
3_{i}=(E+p)(a+B F)+\left(3 I^{2} \rho \tau \beta\right) \times F^{-1},
$$

where $\mathrm{E}$ is the bank rate, $\%$; $\mathrm{p}$ is the coefficient of deductions for depreciation, repairs and maintenance of the line; a is a constant of the cost of $1 \mathrm{~km}$ of OL, which depends on the type of poles, OL design, voltage class, monetary units (MU)/km; в is the appreciation index considering variations in the cost of $1 \mathrm{~km}$ of OL depending on the wire cross-section, normalized in the corresponding voltage class, $\mathrm{MU} /\left(\mathrm{km} \cdot \mathrm{mm}^{2}\right) ; \mathrm{F}$ is the wire cross-section, $\mathrm{mm}^{2}$; I is the maximum line current, $A ; \rho$ is the specific resistance of a conductor material, $\mathrm{Ohm} \cdot \mathrm{mm}^{2} / \mathrm{km}$; $\tau$ is the time of maximum losses, h/year; $\beta$ is the unit cost of power losses, $\mathrm{MU} /(\mathrm{kWh})[13]$.

In view of the fact that the technical and economic models of OL are similar in terms of the similarity theory, the ratio of the previous discount costs to the following within the same parameters series will be identical [13], which is a prerequisite for constructing the parameters series of wire cross-sections of OL:

$$
\frac{\frac{3_{i+1}}{i}}{3_{\frac{i}{i-1}}}=\frac{K_{i+1} r_{i}-K_{i} r_{i+1}}{K_{i} r_{i-1}-K_{i-1} r_{i}} \frac{r_{i-1}-r_{i}}{r_{i}-r_{i+1}} \equiv i d e m,
$$

where $\mathrm{r}_{\mathrm{i}}$ is the resistance of the $i$-th wire; $\quad$ is investments in the $\mathrm{i}$-th line [3].

According to the theory of similarity, the author used the criteria-based method $[3,4]$ for finding the optimum parameters series in a first approximation, which allowed avoiding the initial information uncertainty. For this, the technical and economic model of OL (1) is written in the form of criteria:

$$
3=\pi_{1} \mathrm{~F}_{*}^{0,25}+\pi_{2} \mathrm{~F}_{*}^{-1}
$$

where $\mathrm{F}$ is the relative value of wire cross-sections; $\pi_{1}$ and $\pi_{2}$ are the similarity criteria.

The model (3) is analyzed using the criteria-based method to justify changes in the analytical relationship of investments and the wire cross-section, which allowed forming the appropriate optimization parameter $\left(\mathrm{F}_{0}\right)$ :

$$
\mathrm{F}_{0}=\left(\frac{\pi_{1} \mathrm{~F}_{2}}{\pi_{2} \mathrm{~F}_{1}}\right)^{0,8}
$$

where $\underset{* 1}{\mathrm{~F}}, \mathrm{~F}_{2}$ are the relative values of adjacent wire cross-sections; $\pi_{1}=4 / 5, \pi_{2}=1 / 5$ are the similarity criteria, determined from systematic procedures of the criteria-based method [3, 13].

To estimate the statistical characteristics of the distribution of the relative value of wire cross-sections F of OL, the "sample" from "general populations" is formed and the assumption is made that the cross-section value in the variability range is a random variable. The experimental design technique, which allows carrying out a limited number of experiments according to a certain plan is the most acceptable to achieve the goal [10]. 
The experiment involved two combinations of the levels of each factor (upper and lower). The coded values of factors are "+" and "_". A full factorial experiment of the $2^{\mathrm{k}}$ type with the total number of experiments of $\mathrm{N}=2^{\mathrm{k}}$, where $\mathrm{k}$ is the number of factors influencing the wire cross-section is conducted. On the basis of matrices of statistical populations, the value of the OL wire cross-sections per unit is formed as the statistical series of distribution of a random variable [10].

The estimate of the expected value of the given distribution is equal to 1 , since the expected value of the parameters in (5) is equal to 1 .

The variance estimate $\overline{\mathrm{D}}_{\mathrm{F}}$ of calculations is equal to:

$$
\overline{\mathrm{D}}_{\mathrm{F}}=\frac{1}{(\mathrm{n}-1)} \sum_{\mathrm{i}-1}^{\mathrm{n}}\left(\mathrm{F}_{*}-\overline{\mathrm{m}}_{\mathrm{F}}\right)^{2},
$$

where $F_{1}$ is the wire cross-section per unit; $\bar{m}_{F}$ is the expected value [10].

4. 3. Research materials and methods that allow determining the impact of the optimum scale of wire cross-sections on the facility reconstruction regulations

It is known that the wire cross-section is a key element of the OL, is selected in the design and influences the PG capacity, which affects the regulations of facility reconstruction, which is due to the load rate and growth variations.

Given the load rate and growth variations over time, economically feasible values of optimization parameters $\mathrm{x}_{\mathrm{j}}, \mathrm{y}_{\mathrm{j}}$ are determined using the criteria-based method:

$$
\begin{aligned}
& \mathrm{x}_{\mathrm{j} 0}=\mathrm{x}\left(\mathrm{R}_{\mathrm{a}}, \mathrm{A}_{\mathrm{i}}\right) ; \\
& \mathrm{y}_{\mathrm{j} 0}=\mathrm{e}\left(\mathrm{R}_{\mathrm{a}}, \mathrm{A}_{\mathrm{i}}\right),
\end{aligned}
$$

where $A_{i}$ is the generalized constant bearing some initial information; $R_{a}$ is the criterion that depends on the initial information.

The examination of the dynamic process in the PG, related to the variations of the optimum parameters over time is of interest.

The initial information involved in (8) and (9) in the form of the generalized constants $A_{i}$ varies with time. And the initial information is represented taking into account the load rate and growth variations, the expressions (8) and (9) will have the form:

$$
\begin{aligned}
& \mathrm{x}_{\mathrm{j} 0}(\mathrm{t})=\prod_{\mathrm{i}=1}^{\mathrm{n}+1}\left[\mathrm{~A}_{\mathrm{i}}(\mathrm{t}) / \pi_{\mathrm{i}}\left(\mathrm{R}_{\mathrm{a}}\right)\right]^{-\frac{\Delta \mathrm{ij}}{\Delta}} ; \\
& \mathrm{y}\left(\mathrm{x}_{0} \mathrm{t}\right)=\prod_{\mathrm{i}=1}^{\mathrm{n}+1}\left[\mathrm{~A}_{\mathrm{i}}(\mathrm{t}) / \pi_{\mathrm{i}}\left(\mathrm{R}_{\mathrm{a}}\right)\right]^{-\frac{\Delta \mathrm{i}}{\Delta}},
\end{aligned}
$$

where $A_{i}$ is the generalized constant bearing some initial information, which varies over time $t$; $\mathrm{R}_{\mathrm{a}}$ is the criterion that depends on the initial information; $\pi_{i}$ is the similarity criterion.

Selection of the generalized constants, which depend in turn on time $t$ does not involve the introduction of a new optimization parameter and the original objective function, since the task is to determine the sensitivity of the optimization parameters to reflect the load rate and growth variations over time.

To analyze the sensitivity of the values of the optimization parameters of the function $\mathrm{x}$ to the variation of $A_{i}$ data over time, it is possible to express their relative values through the relative values of coefficients $A_{i}$ :

$$
\begin{aligned}
& \mathrm{x}_{* 0}(\mathrm{t})=\prod_{\mathrm{i}=1}^{\mathrm{n}+1}\left[\mathrm{~A}_{*}(\mathrm{t}) /{\underset{\mathrm{i}}{*}}_{*}\left(\mathrm{R}_{\mathrm{a}}\right)\right]^{-\frac{\Delta \mathrm{ij}}{\Delta}}, \\
& \underset{*}{\mathrm{y}}\left(\mathrm{x}_{0} \mathrm{t}\right)=\prod_{\mathrm{i}=1}^{\mathrm{n}+1}\left[\underset{*}{\left.\mathrm{~A}_{*}(\mathrm{t}) / \underset{*}{\pi_{\mathrm{i}}}\left(\mathrm{R}_{\mathrm{a}}\right)\right]^{-\frac{\Delta \mathrm{i}}{\Delta}},}\right.
\end{aligned}
$$


where $\mathrm{A}_{*}(\mathrm{t})=\frac{\mathrm{A}_{\mathrm{i}}(\mathrm{t})}{\mathrm{A}_{\mathrm{i} \delta}(\mathrm{t})}$ are the relative values of coefficients $\mathrm{A}_{\mathrm{i}}$ taking into account variations over time; $\pi_{i}\left(R_{a}\right)=\pi_{i}\left(R_{a}\right) / \pi_{i \delta}\left(R_{a}\right)$ are the similarity criteria, depending on the initial information.

These expressions allow tracking variations in appropriate parameter values taking into account the load rate and growth variations over time.

The coefficients $A_{1} A_{2}$ depend on the variations over time as follows:

$$
\mathrm{A}_{1}=\frac{\mathrm{A}_{1}^{\prime}}{\mathrm{P}}, \mathrm{A}_{1}=\frac{\mathrm{A}_{2}^{\prime}}{\mathrm{P}}
$$

where $\mathrm{P}$ is the function of variations in the load density, which varies according to the law:

$$
\mathrm{P}=\mathrm{P}_{0}(1+\mathrm{q})^{\mathrm{t}}
$$

where $\mathrm{q}$ is the electric load variation; $\mathrm{P}_{0}$ is the initial load density.

Given the introduced generalized constant (14), the discount costs (5) and the wire cross-section (6) have the form:

$$
\begin{gathered}
\underset{*}{3}=\left(\mathrm{A}_{1}\right)^{\pi_{1}}\left(\mathrm{~A}_{*} \mathrm{P}^{2}\right)^{\pi_{2}}, \\
\underset{*}{\mathrm{~F}}=\left(\frac{\underset{* 2}{\mathrm{~A} \cdot \mathrm{P}^{2}}}{\mathrm{~A}_{* 1}^{\mathrm{A}}}\right)^{0,8}
\end{gathered}
$$

or

$$
3_{*}=\mathrm{P}_{*}^{0,4}, \underset{*}{\mathrm{~F}}=\mathrm{P}_{*}^{1,6}
$$

where $\pi_{1}=0,4 ; \pi_{2}=1,6$ are the similarity criteria, determined from systematic procedures of the criteria-based method $[3,4,6]$.

Using the law of the load density variation (15) over the time $t$ and the expressions (16) and (17) in a relative form, we write

$$
\underset{*}{\mathrm{P}}(1+\mathrm{q})^{\mathrm{t}}=\mathrm{F}_{*}^{0,625}
$$

where $\mathrm{q}$ is the average value of the load growth.

The obtained expression shows the variation of the relative value of the wire cross-section at a given nature of the load.

To analyze the variation in the relative value of the wire cross-section, the value of the wire cross-section per year of construction and commissioning of the OL $\left(\mathrm{t}_{1}\right)$ is taken as the reference cross-section $\mathrm{F}_{6}\left(\mathrm{~F}_{1}\right)$, and the wire cross-section $\mathrm{F}_{2}$ for the reconstruction period of the $\mathrm{OL}\left(\mathrm{t}_{2}\right)$ is taken as the following cross-section. The ratio of these cross-sections is nothing else than the scale growth

factor of the parameters series of wire cross-sections $\mathrm{K}=\frac{\mathrm{F}_{2}}{\mathrm{~F}_{6}}=\underset{*}{\mathrm{~F}}$.
Then:

$$
\begin{aligned}
& \mathrm{P}(1+q)^{\mathrm{t}_{1}}=\mathrm{F}_{*}^{0,625} ; \\
& \mathrm{P}(1+\mathrm{q})^{\mathrm{t}_{2}}=\mathrm{F}_{*}^{0,625} .
\end{aligned}
$$

According to the similarity theory, the ratio of the load density variations in relative form (19) and (20) to determine the reconstruction regulations is a relatively similar value and has the form:

$$
\frac{\mathrm{t}_{2}}{\mathrm{t}_{1}}=\frac{\ln \mathrm{F}_{2}}{\ln \mathrm{F}_{1}}=\text { Idem. }
$$


The reconstruction time, which is due to the OL capacity and specified load rate $\mathrm{q}$, is:

$$
\mathrm{t}_{0}=0,625 \frac{\ln \mathrm{F}}{\ln (1+\mathrm{q})} .
$$

In this expression, the time $t_{0}$ defines the range from the start of operation until the first reconstruction, which is due to a change in the OL capacity, depending on the wire cross-section (F) and specified load variation rate $(\mathrm{q})[14]$.

\section{The results of the analysis of the parameters series of wire cross-sections for the overhead line design}

The methodological framework outlined in 4. 2. is tested on the example of $10 \mathrm{kV}$ OL in accordance with their length.

The analysis by the criteria-based method showed that, depending on the error of the initial data ( $\delta$ from $\pm 5 \%$ to $\pm 10 \%$ ), the scale growth factor of the parameters series of wire cross-sections of $\mathrm{OL}(\mathrm{K}=\mathrm{F})$ can be obtained in the first approximation setting one or another value.

The results of justification of the scale growth factor of the parameters series of wire cross-sections of OL are presented in Table 3.

\section{Table 3}

The results of justification of the scale growth factor of the parameters series of wire cross-sections of $10 \mathrm{kV}$ OL

\begin{tabular}{ccc}
\hline$\delta, \%$ & $F$ \\
\hline 5 & 1,34 \\
6 & 1,58 \\
7 & 0,17 \\
8 & 1,83 \\
9 & 2,09 \\
10 & 2,23
\end{tabular}

Studies have shown that in justifying the scale growth factor of the parameters series of wire cross-sections of $\mathrm{OL}$, the error of performance characteristics plays a significant role and $\mathrm{K}=\mathrm{F} \approx 2$ is the most appropriate ratio, which will allow developing the optimum scale of wire cross-sections.

To evaluate the statistical characteristics of the distribution of the relative value of wire cross-sections of $10 \mathrm{kV} \mathrm{OL}$, the statistical series of the distribution of the random variable of the wire cross-section are built, provided that the parameters vary in the following ranges: $10 \mathrm{kV}-$ $\mathrm{P}=(0.46 \div 1.54) ; \mu=(0.72 \div 1.28) ; \kappa=(0.5 \div 1.5) ; \cos \varphi=(0.99 \div 1.01)$.

To determine the range of falling of the relative wire cross-section of $10 \mathrm{kV} \mathrm{OL}$, the assumption is made that the law of variation of the cross-section distribution density is close enough to the log-normal law at the ends of the confidence ranges. The range is estimated with a sufficiently high probability of $\mathrm{P}=0.95$ with the error $\delta$ from $\pm 5 \%$ to $\pm 10 \%$. The results of determining the range of falling of the relative wire cross-section of OL are presented in Table 4.

\section{Table 4}

The results of determining the range of falling of the relative wire cross-section of $10 \mathrm{kV} \mathrm{OL}$

\begin{tabular}{cc}
\hline$\delta, \%$ & $l_{i}$ \\
\hline 5 & $0,73 \div 1,27$ \\
6 & $0,67 \div 1,33$ \\
7 & $0,60 \div 1,4$ \\
8 & $0,55 \div 1,45$ \\
9 & $0,48 \div 1,52$ \\
10 & $0,41 \div 1,58$
\end{tabular}


The hypothesis $\mathrm{H}_{0}$ is tested using the Pearson's chi-squared test (2). The results of hypothesis testing are presented in Table 5.

Table 5

The results of hypothesis testing by the Pearson's chi-squared test for $10 \mathrm{kV} \mathrm{OL}$

\begin{tabular}{ccc}
\hline$\delta \%$ & $\chi^{2}$ & $\mathrm{P}\left(\chi^{2}\right)$ \\
\hline 5 & 9,6 & 0,537 \\
6 & 9,7 & 0,564 \\
7 & 10,1 & 0,463 \\
8 & 10,2 & 0,472 \\
9 & 10,3 & 0,481 \\
10 & 9,5 & 0,525
\end{tabular}

The results of determining the variance estimate (7) depending on the error of performance characteristics are presented in Table 6.

\section{Table 6}

The results of determining the variance estimate depending on the error of performance characteristics for $10 \mathrm{kV} \mathrm{OL}$

\begin{tabular}{cc}
\hline$\delta, \%$ & $\mathrm{D}$ \\
\hline 5 & 0,0216 \\
6 & 0,0315 \\
7 & 0,0434 \\
8 & 0,0576 \\
9 & 0,0743 \\
10 & 0,0935
\end{tabular}

Using the Pearson's chi-squared test (Table 5) and the variance estimate (Table 6), it is revealed that the introduced hypothesis $\mathrm{H}_{0}$ does not contradict the actual data (p. 4. 1).

In further studies, using the methodological framework, outlined in 4.3 and the resulting scale growth factor of the parameters series of wire cross-sections of $10 \mathrm{kV}$ OL (Table 3 ) at a given nature of the load, the effect of the optimum scale of the wire cross-sections on the facility reconstruction regulations is determined.

The calculations, whose results are presented in Table 7 are carried out with the error $\delta$ from $\pm 5 \%$ to $\pm 10 \%$.

Table 7

Reconstruction regulations of $10 \mathrm{kV}$ OL depending on the scale growth factor of wire cross-sections

\begin{tabular}{ccc}
\hline$\delta, \%$ & $\mathrm{~F}_{2}$ & $\mathrm{t}$ \\
\hline 5 & 1,58 & 1,36 \\
6 & 1,7 & 1,58 \\
7 & 1,83 & 1,8 \\
8 & 1,96 & 2,0 \\
9 & 2,09 & 2,2 \\
10 & 2,23 & 2,4
\end{tabular}


From the analysis of the calculation results (Table 7), it follows that the reconstruction regulations are increased by 2 times.

Thus, the use of the optimum scale of wire cross-sections in the design affects the regulations of reconstruction, which is due to the load rate and growth variations in the PG.

\section{Discussion of the research results that allow designing the overhead lines taking into account their development prospects}

Analysis of the existing parameter, which characterizes and determines the optimization option of the technical and economic model for the OL design revealed the unreasonableness of using the economic current density as the basic optimization parameter of the technical and economic model of the OL. For this, the hypothesis that the current density distribution is lognormal is introduced and the range of current density values is determined. This range is quite large $(0.1 \div 1.2) \mathrm{A} / \mathrm{mm}^{2}$, so the resulting value can not be assumed as the range of economic stability, since almost any value of the current density in this range will be economically viable, which is obviously incorrect and confirms the need to take into account the discrete nature of the scale of wire cross-sections in the optimization of the technical and economic models of OL for the OL design taking into account their development prospects.

The wire cross-section as the basic optimization parameter of the technical and economic model of the OL is proposed. Analysis of the technical and economic model of the OL is brought to a reduction of the special-purpose task (wire cross-section optimization) and the scale growth factor of wire cross-sections is obtained using the criteria-based method, which allowed avoiding the initial information uncertainty. Taking into account the error of performance characteristics, $\mathrm{K}=\mathrm{F} \approx 2$ is the most appropriate ratio. This ratio provides the optimum scale of wire cross-sections of the OL.

To find the relationship of the relative variation of the initial information on the scale growth factor of wire cross-sections of OL, estimation of the statistical characteristics of the distribution of the relative value of wire cross-sections of OL is carried out. The introduced hypothesis of a log-normal distribution law is tested using the Pearson's chi-squared test, which confirmed that the introduced hypothesis does not contradict the actual data.

Using the theory of similarity and the resulting ratio at a given nature of the load, it is determined that using the optimum scale of wire cross-sections of OL increases the period until the required reconstruction, which is due to the load rate and growth variation in the PG by 2 times.

The materials presented in the paper were discussed at the International scientific and practical conference "The problems of energy supply and energy saving in the agricultural sector of Ukraine” (Kharkiv, 2015) [15].

\section{Conclusions}

In the analysis of the parameters series of wire cross-sections for the overhead power line design taking into account their development prospects the author solved the following tasks:

- existing parameter that characterizes and determines the optimization option of the technical and economic model for the overhead line design, which allowed showing the unreasonableness of using the economic current density as the basic optimization parameter of the technical and economic model of overhead lines is investigated;

- the wire cross-section as the basic optimization parameter of the technical and economic model of overhead lines is proposed, and the scale growth factor of the parameters series of wire cross-sections is obtained by the criteria-based method, which allowed developing the optimum scale of wire cross-sections;

- estimation of the statistical characteristics of the distribution of the relative value of wire cross-sections is carried out and the introduced hypothesis of a log-normal law of the current density distribution is tested using the Pearson's chi-squared test for finding the relationship of the relative variation of the initial information on the scale growth factor of wire cross-sections;

- the effect of the optimum scale of wire cross-sections on the regulations of reconstruction, which is due to the load rate and growth variations in the power grid is determined. 


\section{References}

[1] Manjure, D. P., Makram, E. B. (2003). Optimal load curtailment as a bi-criteria program. Electric Power Systems Research, Vol. 66, Issue 2, 155-161. doi: 10.1016/s0378-7796(03)00079-8

[2] Gudapati Sambasiva Rao. (2015). Unification of DG units to the power grid. LAP LAMBERT Academic Publishing, 112.

[3] Lezhnyuk, P. D., Cheremisin, M. M., Cherkashina, V. V. (2013). Unifikaciya povitryanix linij v umovax rinku dvostoronnix dogovoriv ta balansuvalnogo rinku elektroenergiï. Naukovi praci VNTU, № 4, 1-8. Rezhim dostupu: http://praci.vntu.edu.ua/index.php/praci/article/view/378

[4] Bellman, R. (1960). Dinamicheskoe programmirovanie. Moscow: Izd-vo inostr.lit., 400.

[5] Ximelbau, D. (2007). Nelinejnoe programmirovanie. Moscow: "Mir”, 267.

[6] Lezhnyuk, P. D., Bevz, S. V. (1999). Metodi optimizaciï v elektroenergetici. Kriterialnij metod. Vinnicya: VDTU, 177.

[7] Lezhnyuk, P. D. (2003). Analiz chutlivosti optimalnix rishen v skladnix sistemax kriterialnim metodom. Monografiya. Vinnicya: Universum-Vinnicya, 131.

[8] Lee, K., Hashem Pesaran, M., Smith, Ron (1997). Growth and convergence in a multy-country empirical stochastic Solow model. Journal of applied econometrics, Vol. 12, 357-392.

[9] Balakrishnan, N. (2003). A primer on statistical distributions. A JOHN WILEY \& SONS, 297.

[10] Dzhonson, N., Lion, F. (1981). Statistika i planirovanie eksperimenta v texnike i nauke. Metody planirovaniya eksperimenta. Moscow: Mir, 520.

[11] Blok, V. M. (1986). Elektricheskie seti i sistemy. Moscow: Vyssh.shk., 430.

[12] Ventcel, E. S. (2003). Teoriya veroyatnostej. Moscow: Izdatelskij centr «Akademiya», 448.

[13] Bondarenko, V. O., Cheremisin, N. M., Cherkashina, V. V. (2013). Sistemnij pidxid peredproektnoï ocinki povitryanix linij v umovax rinkovix vidnosin. Monografiya - Kharkiv: Fakt, 259.

[14] Cherkashina, V. V. (2014). Faktor vremeni v stratPGii usovershenstvovaniya elektricheskix setej. Elektrotexnika i Elektromexanika, № 3, 65-68.

[15] Programma mizhnarodnoï naukovo-praktichnoï konferenciï "Problemi energozabezpechennya ta energozberezhennya v APK Ukraïni”. Kharkiv, 2015. 